\title{
Materials science and biophysics applications at the ISOLDE radioactive ion beam facility
}

\author{
U. Wahl*
}

Instituto Tecnológico e Nuclear, Estrada Nacional 10, 2686-953 Sacavém, Portugal, and Centro de Física Nuclear da Universidade de Lisboa, Av. Prof. Gama Pinto 2, 1649-003 Lisboa, Portugal

\begin{abstract}
The ISOLDE isotope separator facility at CERN provides a variety of radioactive ion beams, currently more than 800 different isotopes from $\sim 65$ chemical elements. The radioisotopes are produced on-line by nuclear reactions from a $1.4 \mathrm{GeV}$ proton beam with various types of targets, outdiffusion of the reaction products and, if possible, chemically selective ionisation, followed by $60 \mathrm{kV}$ acceleration and mass separation. While ISOLDE is mainly used for nuclear and atomic physics studies, applications in materials science and biophysics account for a significant part (currently $\sim 15 \%$ ) of the delivered beam time, requested by 18 different experiments. The ISOLDE materials science and biophysics community currently consists of $\sim 80$ scientists from more than 40 participating institutes and 21 countries.

In the field of materials science, investigations focus on the study of semiconductors and oxides, with the recent additions of nanoparticles and metals, while the biophysics studies address the toxicity of metal ions in biological systems.

The characterisation methods used are typical radioactive probe techniques such as Mössbauer spectroscopy, perturbed angular correlation, emission channeling, and tracer diffusion studies. In addition to these "classic" methods of nuclear solid state physics, also standard semiconductor analysis techniques such as photoluminescence or deep level transient spectroscopy profit from the application of radioactive isotopes, which helps them to overcome their chemical "blindness" since the nuclear half life of radioisotopes provides a signal that changes in time with characteristic exponential decay or saturation curves.

In this presentation an overview will be given on the recent research activities in materials science and biophysics at ISOLDE, presenting some of the highlights during the last five years, together with a short outlook on the new developments under way.
\end{abstract}

PACS codes: 07.77.-n, 07.77.Ka, 61.72.-y

* Corresponding author, e-mail: uwahl@itn.pt

phone: $++351-21-9946085$

fax: $++351-21-9941525$

\section{Introduction}

The current ISOLDE isotope separator facility [1-3], which is in operation since 1992 at the PS-Booster accelerator, is the third such facility at CERN, following the introduction of the isotope separation on-line (ISOL) technique at CERN in 1967 and the previous ISOLDE-2 facility [4], which was in use from 1974 to 1990 attached to the SC synchro-cyclotron. ISOLDE provides a variety of radioactive ion beams, currently more than 800 different isotopes from $\sim 65$ chemical elements. The radioisotopes are produced on-line by nuclear reactions (fission, fragmentation and spallation) induced by a $1.4 \mathrm{GeV}$ proton beam of $1-2 \mu \mathrm{A}$ with various types of targets such as $\mathrm{UC}_{2}, \mathrm{ThO}, \mathrm{CaO}, \mathrm{ZrO}, \mathrm{YO}$ or $\mathrm{SiC}$ powders, $\mathrm{Ta}$ or $\mathrm{Nb}$ foils, or liquid metals $(\mathrm{Sn}, \mathrm{Pb})$. Following outdiffusion from the heated targets under vacuum, the radioisotopes are ionized, either by plasma ion sources or chemically selective by hot surface 
or laser ionization, followed by $60 \mathrm{kV}$ acceleration and magnetic mass separation. While ISOLDE is mainly used for nuclear and atomic physics studies, applications in materials science and biophysics account for a significant part of the delivered beam time $(\sim 15 \%$ during the last years), and are currently requested by 18 different experiments [4]. Whereas many other radioactive ion beam laboratories are open to research in materials science. ISOLDE is unique due to the wide selection of different isotopes available, which has resulted in a greater variety in experimental techniques than currently established at other radioactive beam facilities. The ISOLDE materials science and biophysics community consists of $\sim 80$ scientists from more than 40 home institutes in 21 countries. Beam time at ISOLDE is awarded based on scientific merit and technical feasibility of the proposed experiments and the community is open to newcomers.

In the field of materials science, investigations focus on the study of semiconductors and oxides, with the recent additions of nanoparticles and metals, while the biophysics studies address the toxicity of metal ions in biological systems. The characterisation methods used are typical radioactive probe techniques such as Mössbauer spectroscopy (MS), perturbed angular correlation (PAC), emission channeling (EC), and tracer diffusion studies. Beta nuclear magnetic resonance ( $\beta$-NMR) is also currently being re-established at ISOLDE. In addition to these "classic" methods of nuclear solid state physics, the standard semiconductor analysis techniques photoluminescence (PL) and deep level transient spectroscopy (DLTS) profit from the application of radioactive isotopes, which helps them to overcome their chemical "blindness" since the nuclear half life of radioisotopes provides a signal that changes in time with characteristic exponential decay or saturation curves.

For the future, as part of the HIE (High Intensity and Energy)-ISOLDE upgrade [5], it is planned to increase the proton driver beam power from $3 \mathrm{~kW}$ to $10 \mathrm{~kW}$, optionally to $30 \mathrm{~kW}$. The resulting increase in radioactive beam intensity will further improve the conditions for applications, making a wider range of radioactive isotopes available as high-intensity beams.

Over the years, the ISOLDE materials science program or parts thereof have been reviewed at various times in the literature [6-16]. This paper gives an overview on the recent ( last 5 years) research activities in materials science and biophysics at ISOLDE, together with a brief outlook on the new developments under way.

\section{Mössbauer effect}

Mössbauer spectroscopy is certainly one of the most widespread nuclear techniques used in materials science, yielding information on the charge state and on the electric field gradients and magnetic fields to which the Mössbauer probe nucleus is exposed in a solid. It is hence not surprising that also among the various radioactive probe techniques at ISOLDE, Mössbauer effect measurements have the longest tradition, being introduced during the late 1970s, and recently reviewed by Weyer [17]. Initial experiments focused on the behaviour of dopants in Si, III-V and II-VI semiconductors using the ${ }^{119} \mathrm{Te}(16 \mathrm{~h}) \rightarrow{ }^{119} \mathrm{Sb}(38 \mathrm{~h}) \rightarrow{ }^{119} \mathrm{Sn}$ and ${ }^{119}$ In $(2.4 \mathrm{~min}) \rightarrow{ }^{119} \mathrm{Sn}$ decays which populate the $24 \mathrm{keV}$ Mössbauer state in ${ }^{119} \mathrm{Sn}$. In 1996, the technique received a considerable boost with the introduction of Mn laser ionisation sources at ISOLDE, which made it possible for the first time to obtain high-intensity isotopically clean beams of ${ }^{57} \mathrm{Mn}$. This short-lived Mn isotope (1.5 min) decays into the well-known ${ }^{57 *} \mathrm{Fe}(98 \mathrm{~ns})$ level, which is the most commonly used Mössbauer state. In comparison to ${ }^{57 *} \mathrm{Fe}$ Mössbauer studies which use long-lived ${ }^{57} \mathrm{Co}(271 \mathrm{~d})$ sources, both in absorption and emission mode, the short half life of ${ }^{57} \mathrm{Mn}$ in combination with the high beam intensity available at ISOLDE (up to $4 \times 10^{8}$ atoms/s corresponding to $\sim 60 \mathrm{pA}$ ) allow for several orders of magnitude faster data taking, making it possible to record hundreds of Mössbauer spectra per day, which is not possible in any other radioactive ion beam facility. Since then, ${ }^{57} \mathrm{Mn} \rightarrow{ }^{57} \mathrm{Fe}$ Mössbauer 
experiments have been undertaken in a large variety of semiconductors and oxides during the last couple of years, with a focus on $\mathrm{Si}, \mathrm{Si}_{x} \mathrm{Ge}_{1-x}$ [18], diamond [19] and especially $\mathrm{ZnO}$ [2023] but also in some geological sampes [24].

The example which will be briefly discussed here is on local magnetism at dilute $\mathrm{Fe}$ atoms in ion-implanted $\mathrm{ZnO}$ [20], where ${ }^{57} \mathrm{Mn} \rightarrow{ }^{57} \mathrm{Fe}$ Mössbauer spectra were recorded during the implantation of low fluences $\left(<10^{12} \mathrm{~cm}^{-2}\right)$ of ${ }^{57} \mathrm{Mn}$ at various temperatures (Fig. 1). For implantation temperatures below $600 \mathrm{~K}$ the Mössbauer spectra show clearly a pronounced sextet resulting from magnetic interaction of $\mathrm{Fe}^{3+}$, on which two doublets D2 and D3 are superposed, resulting from quadrupole-split $\mathrm{Fe}^{2+}(\mathrm{Zn})$ and interstitial $\mathrm{Fe}_{i}$, respectively. In addition two distributions Dist. II and Dist. III of magnetic signals were seen. For higher implantation temperatures the magnetic interaction gradually disappears until finally at $770 \mathrm{~K}$ only the weakly split D2 quadrupole doublet remains, witch was interpreted as substitutional $\mathrm{Fe}^{2+}(\mathrm{Zn})$ on $\mathrm{Zn}$ sites.

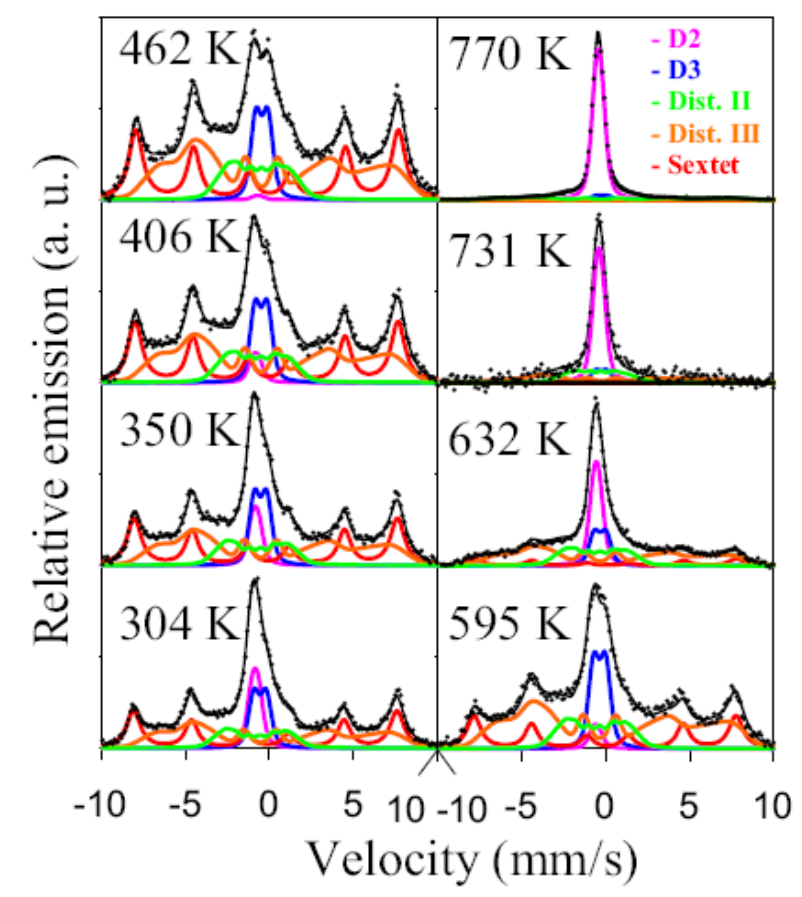

Fig. 1: On-line Mössbauer spectra from the ${ }^{57} \mathrm{Mn} \rightarrow{ }^{57} \mathrm{Fe}$ decay obtained in $\mathrm{ZnO}$ as a function of implantation temperature. The solid black lines are fits to the data points resulting from the superposition of the various contributions shown in colour, as is explained in the text. Reprinted with permission from Ref. [20]. (C) 2007, American Institute of Physics.

While it was not possible to determine from the measured data in Ref. [20] whether ferromagnetism or paramagnetism was responsible for the magnetic sextet seen, this was recently achieved by the same group by means of measuring the angular dependence of the Mössbauer spectra in an external magnetic field [23]. According to these new data the coupling is clearly paramagnetic and ferromagnetism could be ruled out, thus obviously reducing the perspectives for $\mathrm{ZnO}: \mathrm{Fe}$ to act as a true dilute magnetic semiconductor. In addition, the disappearance of the magnetic component at higher temperatures was attributed to spin-lattice relaxation of magnetic $\mathrm{Fe}^{3+}(\mathrm{Zn})$ with unusually long relaxation times.

\section{Perturbed Angular Correlation}

The method of perturbed angular correlation (PAC) is also used at ISOLDE, since the early 1980 s as $\gamma \gamma$-PAC, while during the mid 1990s also e $\gamma$-PAC was introduced. PAC allows 
measuring the electric field gradient (EFG) and the magnetic field that a suited probe nucleus experiences on its lattice site in a solid. Initially the bulk of the experiments at ISOLDE concentrated on semiconductors and on metal surfaces, and has been well reviewed in the past [7-16]. During the last couple of years, the PAC work at ISOLDE in the field of semiconductors has concentrated on experiments using the probes ${ }^{111} \mathrm{In},{ }^{111 \mathrm{~m}} \mathrm{Cd},{ }^{115} \mathrm{Cd},{ }^{117} \mathrm{Cd}$, and ${ }^{111} \mathrm{Ag}$ in the nitride semiconductors $\mathrm{GaN}$ and $\mathrm{AlN}$. The general aim is to better characterize the properties of In, $\mathrm{Cd}$ and $\mathrm{Ag}$ impurities in nitrides (In is of particular relevance for an understanding of the technologically important ternary nitride $\operatorname{In}_{x} \mathrm{Ga}_{1-\gamma} \mathrm{N}$ ), but also to distinguish In-specific effects in PAC by means of comparing it to $\mathrm{Cd}$ and $\mathrm{Ag}$ probes. Another experiment is exploring the feasibility of PAC with the rare earth probes ${ }^{147} \mathrm{Pm},{ }^{147} \mathrm{Eu},{ }^{149} \mathrm{Eu}$, ${ }^{156} \mathrm{Gd},{ }^{172} \mathrm{Yb},{ }^{169} \mathrm{Tm},{ }^{172} \mathrm{Yb}$ in nitride semiconductors and using an entirely new PAC spectrometer with all-digital electronics and data acquisition.
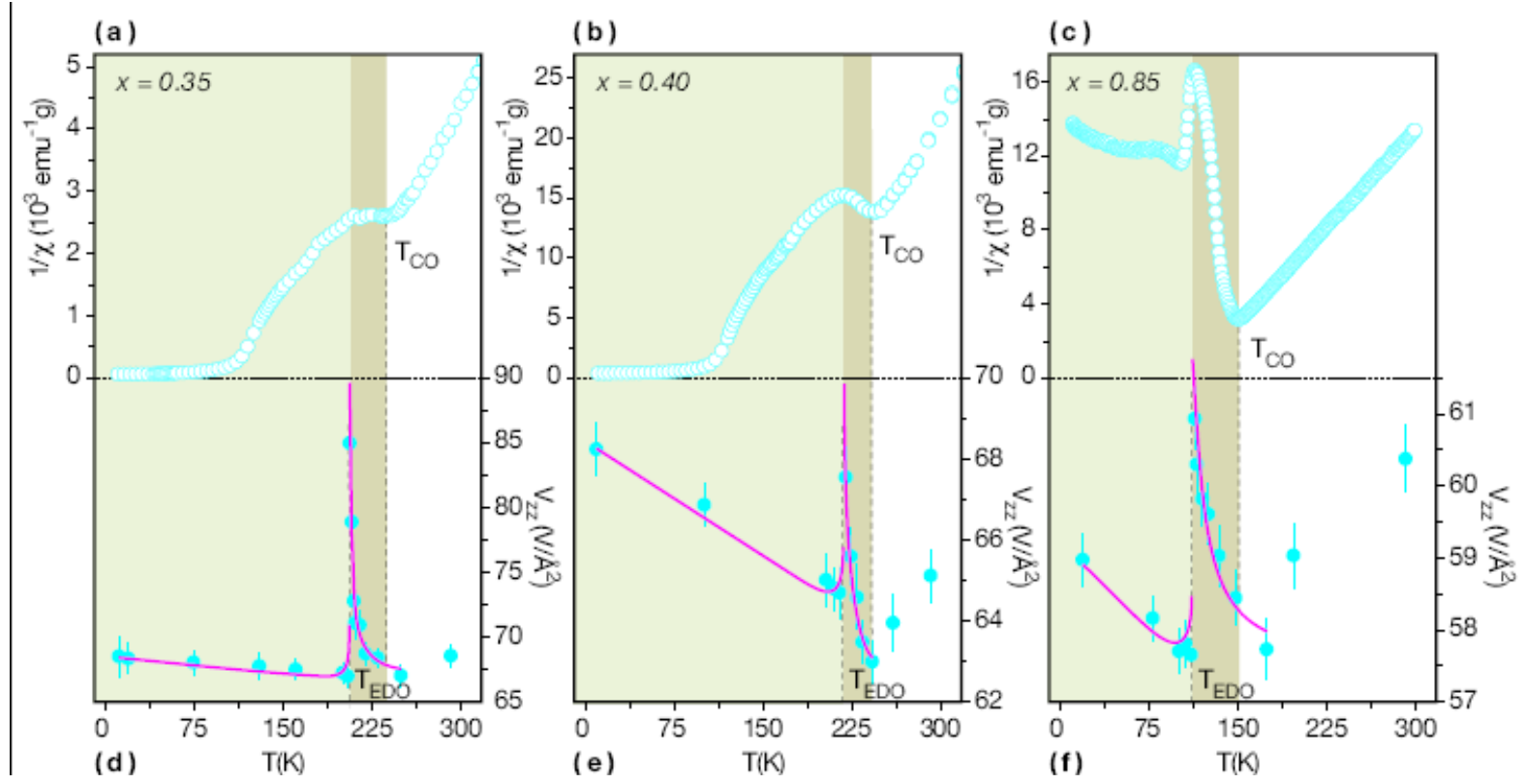

Fig. 2: Top row: temperature dependence of the inverse magnetic susceptibility $1 / \chi$ for $\operatorname{Pr}_{1-\chi} \mathrm{Ca}_{x} \mathrm{MnO}_{3}$ samples with $x=0.35$ (a), $x=0.40$ (b), and $x=0.85$ (c). Bottom row: temperature dependence of the electric field gradient $V_{Z Z}$ seen by the radioactive ${ }^{111 \mathrm{~m}} \mathrm{Cd}$ nucleus and correspondent fits below the charge order transition using the Landau theory of phase transitions for $x=0.35$ (d), $x=0.40$ (e), and $x=0.85$ (f). Reprinted with permission from Ref. [26]. (C) 2008, American Physical Society.

The example which is to be discussed in the following, however, is from the field of PAC in oxides, which has gained increasing importance during recent years and provided some valuable results regarding phase transitions in manganites [25-27]. The mixed valence compound $\mathrm{Pr}_{1-x} \mathrm{Ca}_{x} \mathrm{MnO}_{3}$ has an orthorhombic distorted perovskite structure and belongs to the class of multiferroic oxides, i.e. it shows a combination of ferroelectric and magnetic orders, which in this case is associated with the occurrence of $\mathrm{Mn}^{3+} / \mathrm{Mn}^{4+}$ valence charge order in the material. The PAC probe ${ }^{111 \mathrm{~m}} \mathrm{Cd}(48.5 \mathrm{~min})$ was implanted into different $\operatorname{Pr}_{1-x} \mathrm{Ca}_{x} \mathrm{MnO}_{3}$ compounds, where it is incorporated on Ca sites. The electric field gradient experienced by the probe atoms was then measured as a function of temperature [Fig. 2 (d)-(f)] across the charge order (CO) phase transition which was established from the magnetic susceptibility [Fig. 2 (a)(c)]. At low temperatures, in the $\mathrm{CO}$ regime, where the samples are ferroelectric or antiferroelectric, a mild temperature dependence of the main component $V_{Z Z}$ of the EFG is observed, which decreases slowly with increasing temperature until a prominent discontinuity is reached and a sharp upward jump in $V_{Z Z}$ occurs at a temperature TEDO close to but clearly 
below the charge order temperature TCO, followed again by a less sharp decrease. The mild temperature dependence of the EFG below TEDO was ascribed to the onset of electric dipole fluctuations at the probe site and TEDO itself is hence interpreted as the temperature where electric dipole order is lost completely, which surprisingly occurs clearly below the temperature TCO where $\mathrm{Mn}^{3+} / \mathrm{Mn}^{4+}$ valence charge order itself is disappearing. Summarizing, the PAC measurements gave clear evidence for a new phase transition occurring below the charge order transition in $\operatorname{Pr}_{1-x} \mathrm{Ca}_{x} \mathrm{MnO}_{3}$ and it was interpreted in terms of a paraelectric to (anti)ferroelectric first-order phase transition related to electric dipole ordering.

\section{Emission channeling}

The principle of the emission channeling (EC) lattice location method relies on doping single crystals with radioactive probe atoms that decay by the emission of charged particles such as $\alpha, \beta^{-}$or $\beta^{+}$particles or conversion electrons, which, on their way out of the crystal, experience channeling or blocking effects along low-index crystal directions. The resulting anisotropic particle emission yield in the vicinity of major crystallographic directions depends in a characteristic way on the lattice sites occupied by the emitter atoms and is recorded with the aid of position sensitive detectors. In comparison to conventional lattice location techniques by means of ion beam channeling, e.g. Rutherford Backscattering/Channeling $(\mathrm{RBS} / \mathrm{C})$, the main benefit of emission channeling is a roughly four orders of magnitude higher efficiency. An additional and unique advantage is the fact that, provided a suitable radioactive isotope is available, there is no decrease of sensitivity regarding the detection of elements lighter than the host lattices, contrarily to RBS/C. These facts allow one to perform detailed lattice location studies with very good statistical accuracy at low fluences of implanted probe atoms, usually on the same sample as a function of post-implantation annealing temperature, which is not feasible by other methods.
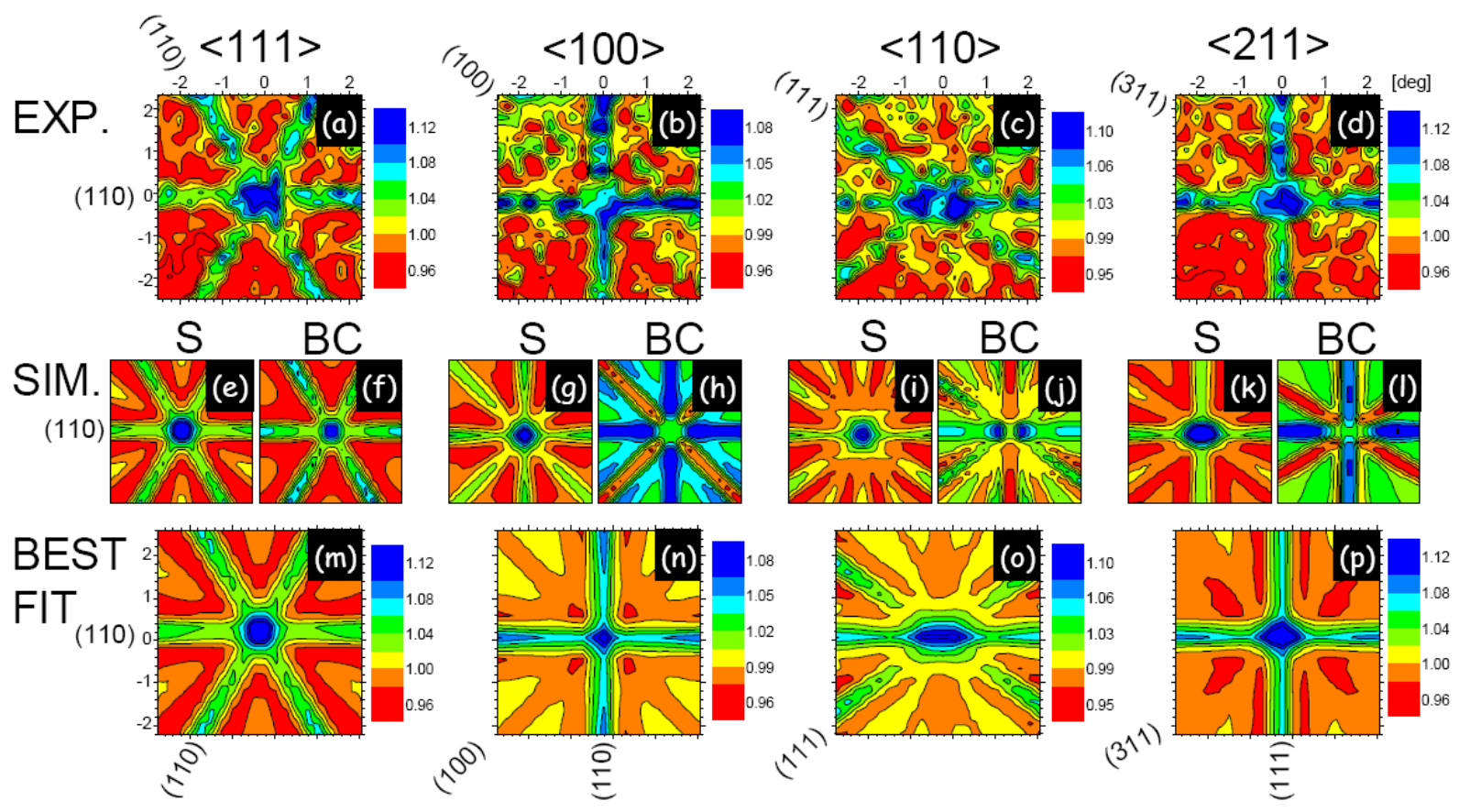

Fig. 3: (a)-(d) Two-dimensional $\beta^{-}$emission channeling patterns from ${ }^{111} \mathrm{Ag}$ in $\mathrm{Ge}$ around the $<111>,<100>$, $<110>$, and $<211>$-axes, following $400{ }^{\circ} \mathrm{C}$ annealing in vacuum; simulated patterns for ${ }^{111} \mathrm{Ag}$ on the $\mathrm{S}$ site and on the BC site, respectively, are shown in panels (e), (f) for $<111>$, (g), (h) for $<100>$, (i), (j) for $<110>$ and (k), (l) for $<211>$-axes; (m)-(p) are the best fits to the experimental patterns, consisting of a superposition of $\sim 20 \% \mathrm{~S}$ and $\sim 37 \%$ BC patterns. From Ref. [39]. (C) 2009 by the American Physical Society. 
Emission channeling has been pursued at ISOLDE since 1985 and the technique received a major boost in 1997, when, in collaboration with detector groups from CERN, position-sensitive detection of electrons was introduced using pixel detectors developed for high-energy physics. During the last five years the EC experiments focused on the lattice location of dopants and impurities in $\mathrm{Si}$ [28-29], $\mathrm{ZnO}$ [30-33], GaN [34-35], AlN [36] and, most recently, also in Ge. In Ge, besides the preferred substitutional sites, up to now the following impurities were found to occupy the so-called bond-center (BC) site: $\operatorname{Er}$ [37], In [38], the transition metals $\mathrm{Fe}, \mathrm{Cu}$ and $\mathrm{Ag}$ [39], and $\mathrm{Sn}$ [40]. By means of investigating the formation energy of defect complexes with the help of density functional theory, the $\mathrm{BC}$ location was identified as foreign atoms inside a double vacancy. Rather than remaining on its substitutional position, this so-called split-vacancy configuration is formed when a substitutional foreign atoms traps a Ge vacancy. As an example we present the $\beta^{-}$emission channeling results of ${ }^{111} \mathrm{Ag}$ in Ge (Fig. 3). The experimental patterns can only be explained by assuming that they result from a superposition of $\mathrm{Ag}$ on substitutional and $\mathrm{BC}$ sites, with the best fit results obtained for $\sim 20 \%$ of ${ }^{111} \mathrm{Ag}$ on $\mathrm{S}$ and $\sim 37 \%$ of ${ }^{111} \mathrm{Ag}$ on $\mathrm{BC}$ sites.

\section{Tracer diffusion}

Tracer diffusion is in fact the oldest technique applying radioisotopes in materials science, being discovered as early as in 1920. At ISOLDE it is in use since the mid 1980s and its principle is very simple. A radioisotope is implanted into the near-surface region of a sample, which is then subjected to thermal annealing inducing diffusion on a macroscopic scale, after which the diffusion profile is obtained by means of sectioning the sample and measuring either the amount of radioactivity removed from or left in the sample. Since radiotracer diffusion studies do not pose very stringent requirements on the radioisotopes apart from being available in sufficient quantities, having a convenient half-life and being detectable by means of gamma or charged particle detectors, suitable radioisotopes can be found for most elements of the periodic system. However, for some elements there only exist very short-lived radioisotopes, e.g. ${ }^{29} \mathrm{Al}$ (6.6 min), which do not allow for long time periods in between isotope production, incorporation into the sample, diffusion annealing, and analysis of the profile. In order to perform experiments with short-lived isotopes, sophisticated on-line radiotracer setups have been constructed, which allow to carry out all steps in a minimum of time. During recent years the tracer diffusion studies have investigated transition metal diffusion in CdTe [41-44] and diffusion of $\mathrm{Be}, \mathrm{Ga}$, and $\mathrm{Sn}$ in $\mathrm{Ge}$ and $\mathrm{SiGe}$ alloys [45-48], of Be in glassy carbon [49] and of $\mathrm{Mn}$ in GaAs [50].

Figure 4 shows concentration profiles of the radiotracers ${ }^{111} \mathrm{Ag},{ }^{67} \mathrm{Cu},{ }^{193} \mathrm{Au}$, and ${ }^{24} \mathrm{Na}$ measured in CdTe crystals after implantation and subsequent diffusion under external $\mathrm{Cd}$ pressure [41-44]. All profiles are symmetrical with respect to the center of the crystal and exhibit layers with low concentrations of diffusers ( $\sim 20$ times lower than in the center) extending to a depth of 100-250 $\mu \mathrm{m}$ below both surfaces. Since the diffusion starts from an almost $\delta$-like implanted profile on one surface as compared to the thickness of the crystal, the dopant atoms have to diffuse from low to high concentration in order to form the profiles shown in Fig. 4. Such unusual diffusion behaviour is called uphill diffusion.

The uphill diffusion is due to the fact that the elements shown in Fig. 4 are all fast interstitial diffusers that also act as electrically active interstitial donors, e.g. $\mathrm{Ag}_{\mathrm{i}}{ }^{+}, \mathrm{Na}_{\mathrm{i}}{ }^{+}$. The CdTe crystals are initially Te-rich but upon diffusion under $\mathrm{Cd}$ atmosphere the surface regions become Cd-rich due to the indiffusion of $\mathrm{Cd}$ interstitials $\mathrm{Cd}_{\mathrm{i}}$. Since the intrinsic point defects $\mathrm{Cd}_{\mathrm{i}}$ and $\mathrm{V}_{\mathrm{Cd}}$ form shallow donor and acceptor levels in the band gap, respectively, upon diffusion under $\mathrm{Cd}$ atmosphere pn-junctions are established on both sides of the crystal, i.e. $n$ type regions with $\mathrm{Cd}$-excess near both surfaces and a $p$-type region with Te-excess in the 
center. In thermal equilibrium with the host crystal, the dopant profile mirrors the profile of the electric potential across the crystal.

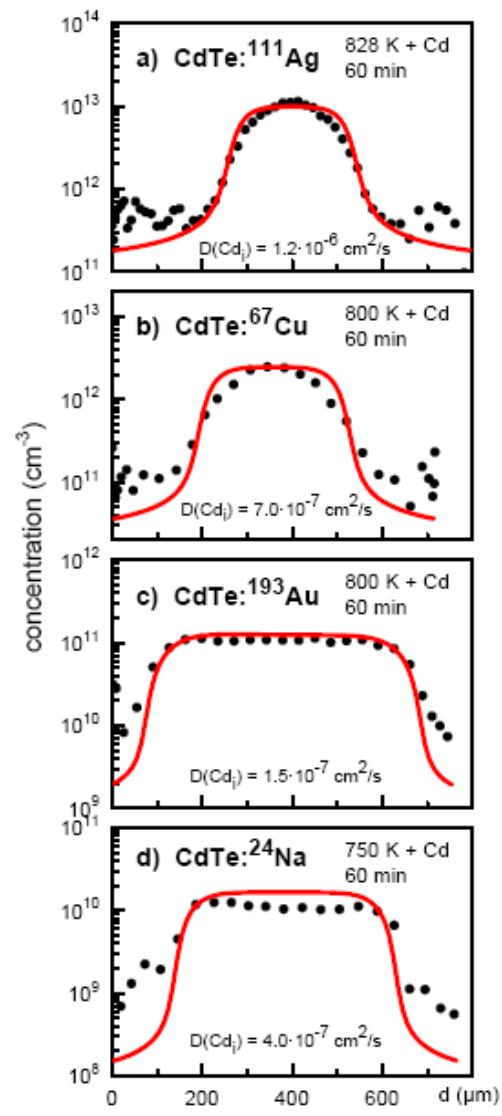

Fig. 4: Uphill diffusion profiles measured for the radiotracers ${ }^{111} \mathrm{Ag},{ }^{67} \mathrm{Cu},{ }^{193} \mathrm{Au}$, and ${ }^{24} \mathrm{Na}$ in $\mathrm{CdTe}$ annealed under $\mathrm{Cd}$ atmosphere at the specified temperatures. The solid lines are simulations according to the model described in Ref. [44]. Note that the left and right end of the $d$-axis correspond to the two surfaces of the $\sim 750 \mu \mathrm{m}$ thick samples.

\section{Biophysics}

Biophysics and medical applications also have a long tradition at ISOLDE. While the production of radioisotopes for small-scale clinical studies, e.g. ${ }^{149} \mathrm{~Tb}(4.1 \mathrm{~h})$ and other lanthanide nuclides as " $\alpha$-knifes" in cancer therapy [51], has been pursued in the past, it is currently not active but a proposal has been presented to resume this activity at the upgraded HIE-ISOLDE facility. On the other hand, biophysics studies using the PAC technique with the probe nuclei ${ }^{199 \mathrm{~m}} \mathrm{Hg}(43 \mathrm{~min})$ and ${ }^{111 \mathrm{~m}} \mathrm{Cd}$ have been active at ISOLDE since the beginning of the 1990s and ISOLDE-produced results also form part of the general review on the subject by Hemmingsen [52]. The biophysics PAC experiments generally aim to identify the binding sites, ligands, and dynamic interactions of probe atoms attached to large biomolecules under specific conditions such as temperature, ambient solution, $\mathrm{pH}$, etc. For that purpose, the radioisotopes are implanted in ice held at liquid nitrogen temperature, which is then molten after removing the beam catcher from the vacuum so that the radioactive probes are directly available for biochemical processing in aqueous solution using a small chemistry lab located on-site. PAC spectra are then typically recorded by 6-detector setups that are shared with the materials science community. Initially, in the work of Butz and Tröger, the subject were blue copper proteins doped with ${ }^{199 \mathrm{~m}} \mathrm{Hg}$ (as is also reviewed in Ref. [52]), while more recently the 
study of Hg-binding peptides and Zn-binding proteins emerged [53-55], both with the general aim to assess the function and toxicity of metal ions in biological systems.

Figure 5 shows the Fourier transforms of the ${ }^{199 m} \mathrm{Hg}$ PAC spectra corresponding to the $\mathrm{pH}$ titration of a solution containing the peptide TRI L9C and $\mathrm{Hg}(\mathrm{II})$ ions (stable $\mathrm{Hg}$ carriers plus ${ }^{199 \mathrm{~m}} \mathrm{Hg}$ ) at a peptide/ $\mathrm{Hg}$ (II) ratio of $12: 1$ [53]. While only one nuclear quadrupole interaction type (characterized by one single frequency triplet) is found for the experiment at $\mathrm{pH}$ 6.5, upon increasing the $\mathrm{pH}$ of the solution another set of signals appears in the PAC spectra, which then remains responsible for the major part $(90 \%)$ of the signal at $\mathrm{pH} 8.7$. At this $\mathrm{pH}$ value, the fitted PAC parameters reveal the formation of a complex with a trigonalplanar $\left[\mathrm{Hg}(\mathrm{TRI} \text { L9C })_{3}\right]$ coordination geometry, while the fitted PAC parameters for the species at low $\mathrm{pH}$ indicate the presence of a linear [Hg(TRI L9C $)_{2}$ ] coordination geometry, supporting the formation of a bisthiolato- $\mathrm{Hg}(\mathrm{II})$. The results support the existence of a bisthiolato- $\mathrm{Hg}(\mathrm{II})$ complex encapsulated within a three-stranded coiled coil and a stepwise aggregationdeprotonation mechanism. For the future, it is planned to extend the ISOLDE biophysics experiments to in vivo studies, i.e. by introducing the PAC probes into living plants, as already initiated by Heinz et al. [54].

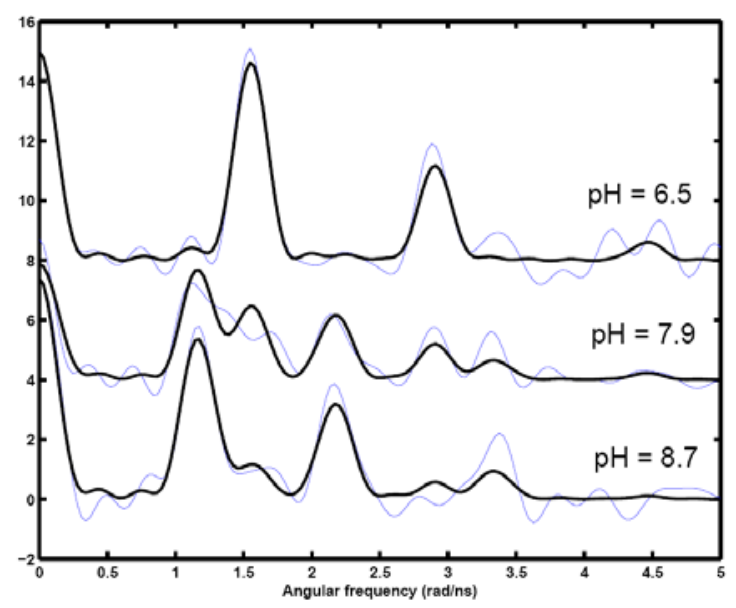

Fig. 5: Fourier transform of ${ }^{199 \mathrm{~m}} \mathrm{Hg}$ PAC spectra of solutions containing TRI L9C $(125-130 \mu \mathrm{M})$ and $\mathrm{HgCl}_{2}$ $(10.8 \mu \mathrm{M})$ at different $\mathrm{pH}$ values. The thin blue lines represent the Fourier transform of the experimental data and the thick black lines represent the fit. Reprinted with permission from Ref. [52]. (C) 2008 Wiley-VCH Verlag $\mathrm{GmbH} \& \mathrm{Co}$. KGaA. Reproduced with permission.

\section{4b) Photoluminescence}

Photoluminescence (PL) is a classical spectroscopy technique which is widely used in semiconductor physics in order to detect optical transitions involving electronic energy levels in or near the band gap. While PL is highly sensitive to low concentrations of optically active defects, it does not provide direct microscopic information about the chemical identity of the optical centers responsible for the signals. Correlating the intensity of PL lines with the radioactive decay of implanted isotopes in the sample allows such an identification. Besides PL, which was introduced during the mid-1990s at ISOLDE, also deep level transient spectroscopy (DLTS) is being used there with radioactive isotopes [56], and Laplace DLTS has been added this year. While Hall effect and conductivity measurements can in principle also benefit in a similar way from the use of radioactive isotopes, they were previously used but are currently not practiced at ISOLDE. As an example how PL can overcome its chemical blindness by means of using radiotracers, we present a study [57] that allowed unambiguously identifying the Ga donor-related $\mathrm{PL}$ signals $\mathrm{I}_{8}$ and $\mathrm{I}_{1}$ in $\mathrm{ZnO}$, together with the identification of a new Ge-related double donor. For the purpose of this study, $\mathrm{ZnO}$ samples were implanted 
with ${ }^{73} \mathrm{Ga}\left(t_{1 / 2}=4.76 \mathrm{~h}\right)$ and with ${ }^{72} \mathrm{Zn}(46.3 \mathrm{~h}) \rightarrow{ }^{72} \mathrm{Ga}(14.1 \mathrm{~h})$, respectively. Following annealing at $1050{ }^{\circ} \mathrm{C}$ under $\mathrm{O}_{2}$ atmosphere, the intensity of several PL lines was monitored as a function of time (Fig. 6). While the time dependence of the $\mathrm{I}_{8}$ and $\mathrm{I}_{1}$ lines followed the amount of radioactive ${ }^{73} \mathrm{Ga}$ or ${ }^{72} \mathrm{Ga}$ in the sample, a new double-donor signal $\mathrm{DD}_{2}$ could be identified as being due to the amount of stable ${ }^{73} \mathrm{Ge}$ produced by the decay of ${ }^{73} \mathrm{Ga}$. From the observed time dependence it is also clear that the respective centers contain one Ga or one Ge atom only.

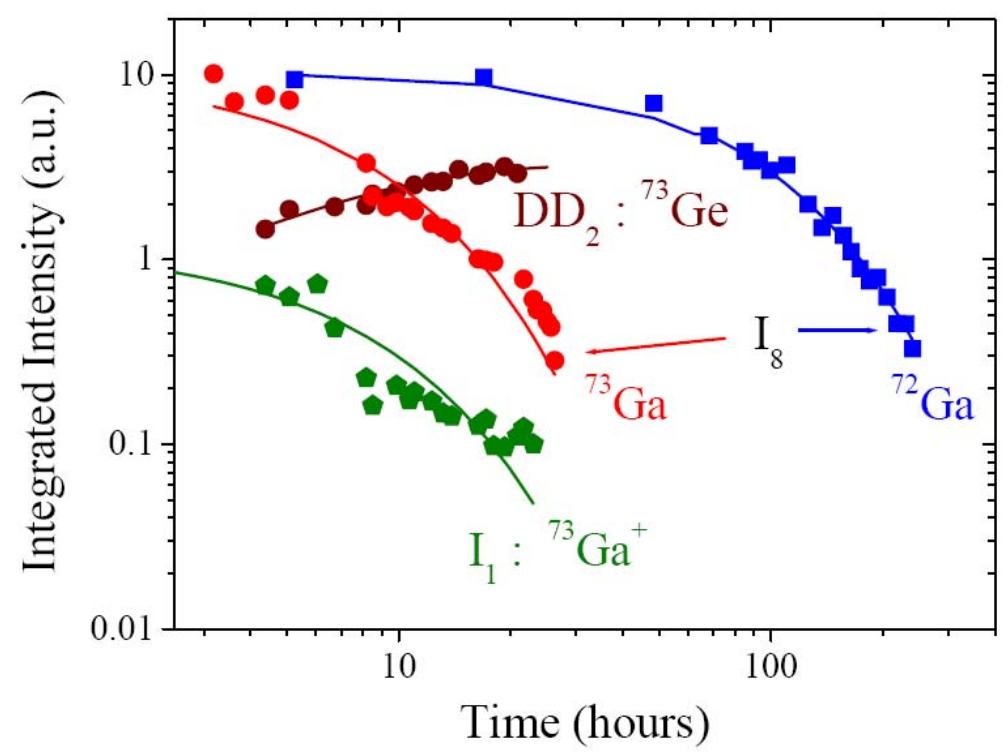

Fig. 6: Time dependence of the intensity of several $\mathrm{PL}$ lines in $\mathrm{ZnO}$ resulting from the ${ }^{73} \mathrm{Ga}\left(t_{1 / 2}=4.76 \mathrm{~h}\right) \rightarrow{ }^{73} \mathrm{Ge}$ (stable) and ${ }^{72} \mathrm{Zn}(46.32 \mathrm{~h}) \rightarrow{ }^{72} \mathrm{Ga}(14.1 \mathrm{~h}) \rightarrow{ }^{72} \mathrm{Ge}$ (stable) decay chains. The fits to the data obtained from the different experiments are modeled using radioactive decay curves as described in Ref. [56]. The red circles and blue squares are the intensity of the $I_{8}$ line from the ${ }^{73} \mathrm{Ga}$ and ${ }^{72} \mathrm{Zn}$ implantations, respectively; the filled brown circles are the data for the growth of the ${ }^{73} \mathrm{Ge}^{\mathrm{D}} \mathrm{D}_{2}$ peak. Also included on the graph are the data for the decay of the line $I_{1}$, which is due to the ionized ${ }^{73} \mathrm{Ga}^{+}$donor $\left(\mathrm{D}^{+} X\right)$.

ISOLDE has recently also been used to implant radioactive isotopes of ${ }^{195} \mathrm{Au}(186 \mathrm{~d}) \rightarrow{ }^{195} \mathrm{Pt}$ (stable) in isotopically pure samples of ${ }^{28} \mathrm{Si}$ [58-59]. In these cases, the chemical identification of PL lines is not made via radioactive decay but is possible due to the extremely narrow line width of PL lines in the $99.99 \%$ isotopically pure $\mathrm{Si}$, allowing to clearly separate the isotope shift of PL lines resulting from different isotopes of the same element. Since there exists only one stable gold isotope in nature $\left({ }^{197} \mathrm{Au}\right)$, the use of ISOLDE was necessary in order to provide a gold isotope of a different mass, with the same samples being useful for the Pt studies after the decay.

\section{Conclusions}

Materials science and biophysics studies have a long tradition at the ISOLDE radioactive ion beam facility, where a variety of different analysis techniques have been established throughout the years, thanks to the diversity, purity and high intensity of the isotope beams available. They represent a valuable addition to the nuclear and atomic physics activities at ISOLDE, in particular since they usually apply isotopes relatively close to stability for which a comparably small amount of beam time is required. The intended upgrades of ISOLDE also aim at further improving the conditions for materials science and biophysics experiments in the future, and interested new users of the facility are most welcome to submit qualified research proposals. 


\section{Acknowledgments}

I thank V. Amaral, J.P. Araújo, J.G. Correia, S. Decoster, M. Deicher, H. Gunnlaugsson, L. Hemmingsen, K. Johnston, A.M.L. Lopes, G. Weyer, Th. Wichert and H. Wolf for valuable discussions and for providing figures from their original works. This work was supported by the Portuguese Foundation for Science and Technology through grants PTDC/FIS/66262/2006 and CERN/FP/109272/2009.

\section{References}

[1] http://isolde.web.cern.ch/ISOLDE/

[2] E. Kugler, D. Fiander, B. Jonson, H. Haas, A. Przewloka, H.L. Ravn, D.J. Simon, K. Zimmer, the ISOLDE collaboration, The new CERN-ISOLDE on-line mass separator facility at the PS-Booster, Nucl. Instr. Meth. B 70 (1992) 41. M. Lindroos, Future plans at ISOLDE, Nucl. Instr. Meth. B 204 (2003) 730.

[3] H.L. Ravn, Experiments with intense secondary beams of radioactive ions, Physics Reports 54 (1979) 201.

[4] https://espace.cern.ch/ISOLDE-SSP/default.aspx

[5] M. Lindroos, P.A. Butler, M. Huyse, K. Riisager, HIE-ISOLDE, Nucl. Instr. Meth. B 266 (2008) 4687.

[6] H. Haas, the ISOLDE collaboration, Condensed matter physics with radioactive ion beams, Nucl. Instr. Meth. B 107 (1996) 349.

[7] D. Forkel, Radioactive isotopes in solid state physics, Nucl. Instr. Meth. B 126 (1997) 396.

[8] J.G. Correia, Radioactive ion beams and techniques for solid state research, Nucl. Instr. Meth. B 136 (1998) 736.

[9] D. Forkel-Wirth, Radioactive ion beams in solid state physics, Phil. Trans. R. Soc. Lond. A 356 (1998) 2137.

[10] D. Forkel-Wirth, Exploring solid state physics properties with radioactive isotopes, Rep. Prog. Phys. 62 (1999) 527.

[11] Th. Wichert, M. Deicher, Studies of semiconductors, Nuclear Physics A 693 (2001) 327.

[12] M. Deicher, the ISOLDE collaboration, Applications of radioactive ion beams to solid-state physics, Eur. Phys. J. A 15 (2002) 275.

[13] M. Deicher, Radioactive isotopes in solid state physics, Europhysics News 33 (2002) 3.

[14] M. Deicher, G. Weyer, Th. Wichert, the ISOLDE collaboration, Solid state physics at ISOLDE, Hyperfine Interactions 151/152 (2003) 105.

[15] Th. Wichert, Semiconductor studies by radioactive probe atoms, Physica B 326 (2003) 105.

[16] M. Deicher, the ISOLDE collaboration, Characterization of defects in semiconductors using radioactive isotopes, Physica B 389 (2007) 51.

[17] G. Weyer, Defects in semiconductors - results from Mössbauer spectroscopy, Hyperfine Interactions 177 (2007) 1.

[18] D. Naidoo, H. P. Gunnlaugsson, K. Bharuth-Ram, V. V. Naicker, G. Weyer, R. Sielemann, R. Mantovan, M. Fanciulli, ISOLDE Collaboration, 57Fe Mössbauer investigations in p-type silicon germanium single crystals, Hyperfine Interactions 188 (2008) 11.

[19] K. Bharuth-Ram, V.V. Naicker, D. Naidoo, H.P. Gunnlaugsson, R. Mantovan, G. Weyer, M. Dietrich, J.E. Butler, the ISOLDE Collaboration, Mössbauer study of 57Fe in CVD diamond following $57 \mathrm{Mn}$ implantation, Hyperfine Interactions 179 (2008) 17.

[20] G. Weyer, H. P. Gunnlaugsson, R. Mantovan, M. Fanciulli, D. Naidoo, K. Bharuth-Ram, T. Agne, Defectrelated local magnetism at dilute Fe atoms in ion-implanted ZnO, J. Appl. Phys. 102 (2007) 113915.

[21] H.P. Gunnlaugsson, G. Weyer, R. Mantovan, D. Naidoo, R. Sielemann, K. Bharuth-Ram, M. Fanciulli, K. Johnston, S. Olafsson, G. Langouche, Isothermal defect annealing in semiconductors investigated by timedelayed Mössbauer spectroscopy: application to $\mathrm{ZnO}$, Hyperfine Interactions 188 (2008) 85.

[22] T.E. Molholt, R. Mantovan, H.P. Gunnlaugsson, K. Bharuth-Ram, M. Fanciulli, H.P. Gislason, K. Johnston, Y. Kobayashi, G. Langouche, H. Masenda, D. Naidoo, S. Olafsson, R. Sielemann, G. Weyer, Temperature and dose dependence of defect complex formation with ion implanted $\mathrm{Mn} / \mathrm{Fe}$ in $\mathrm{ZnO}$, Physica B 404 (2009) 4820.

[23] H.P. Gunnlaugsson, T.E. Mølholt, R. Mantovan, H. Masenda, D. Naidoo, W. B. Dlamini, R. Sielemann, K. Bharuth-Ram, G. Weyer, K. Johnston, G. Langouche, S. Ólafsson, H.P. Gíslason, Y. Kobayashi, Y. Yoshida, M. Fanciulli, the ISOLDE Collaboration, Paramagnetism in Mn/Fe implanted ZnO, Appl. Phys. Lett. (2010), in print.

[24] H.P. Gunnlaugsson, C. Bender Koch, K. Bharuth-Ram, M. Dietrich, Ö. Helgason, M.B. Madsen, R. Mantovan, D. Naidoo, S. Steinthorsson, L. Vistisen, G. Weyer: Disordered chromite in the Martian meteorite Allan Hills 84001, Hyperfine Interactions, 186 (2008) 9.

[25] J.P. Araújo, A.M.L. Lopes, E. Rita, J.G. Correia, V.S. Amaral, U. Wahl, the ISOLDE Collaboration, Local probe studies on oxides using radioactive isotopes, Materials Science Forum 514 (2006) 1593. 
[26] A.M.L. Lopes, J.P. Araujo, V.S. Amaral, J.G. Correia, Y. Tomioka, and Y. Tokura, New phase transition in the $\mathrm{Pr}_{1-x} \mathrm{Ca}_{x} \mathrm{MnO}_{3}$ system: Evidence for electric polarization in charge ordered manganites, Phys. Rev. Lett. 100 (2008) 155702.

[27] A.M.L. Lopes, J.P. Araujo, T.M. Mendonca, J.S. Amaral, A.M. Pereira, P.B. Tavares, V.S. Amaral, J.G. Correia, Magnetic Hyperfine Field Study in the $\operatorname{Pr}_{1-x} \mathrm{Ca}_{x} \mathrm{MnO}_{3}$ System, Journal of non-crystalline solids 354 (2008) 5315.

[28] U. Wahl, J.G. Correia, E. Rita, J.P. Araújo, J.C. Soares, and the ISOLDE collaboration, Lattice sites of implanted Fe in Si, Physical Review B 72 (2005) 014115.

[29] U. Wahl, J.G. Correia, E. Rita, J.P. Araújo, J.C. Soares, and the ISOLDE collaboration, Fe and Cu in Si: lattice sites and trapping at implantation-related defects, Nuclear Instruments and Methods in Physics Research B 253 (2006) 167.

[30] U. Wahl, E. Rita, J.G. Correia, E. Alves, J.C. Soares, the ISOLDE collaboration, Direct evidence for As as a Zn-site impurity in ZnO, Phys. Rev. Lett. 95 (2005) 215503.

[31] U. Wahl, E. Rita, J.G. Correia, T. Agne, E. Alves, J.C. Soares, and the ISOLDE collaboration, Lattice sites of implanted $\mathrm{Cu}$ and $\mathrm{Ag}$ in $\mathrm{ZnO}$, Superlattices and Microstructures 39 (2006) 229.

[32] U. Wahl, J.G. Correia, S. Decoster, T. Mendonça, Direct evidence for Sb as a Zn site impurity in ZnO, Appl. Phys. Lett. 94 (2009) 261901.

[33] U. Wahl, J.G. Correia, S. Decoster, T. Mendonça, Lattice location of the group V elements As and Sb in ZnO, Physica B 404 (2009) 4803.

[34] B. De Vries, A. Vantomme, U. Wahl, J.G. Correia, J.P. Araújo, W. Lojkowski, D. Kolesnikov, and the ISOLDE collaboration, Lattice site location and annealing behaviour of $\mathrm{Ca}$ and $\mathrm{Sr}$ implanted GaN, Journal of Applied Physics 100 (2006) 023531.

[35] U. Wahl, J.G. Correia, J.P. Araújo, E. Rita, and J.C. Soares, Amphoteric arsenic in GaN, Appl. Phys. Lett. 90 (2007) 181934.

[36] U. Vetter, J.B. Gruber, A.S. Nijjar, B. Zandi, G. Öhl, U. Wahl, B. De Vries, H. Hofsäss, M. Dietrich, the ISOLDE collaboration, Crystal field analysis of $\mathrm{Pm}^{3+}(4 f 4)$ and $\mathrm{Sm}^{3+}(4 f 5)$ and lattice location studies of ${ }^{147} \mathrm{Nd}$ and ${ }^{147} \mathrm{Pm}$ in $w$-AlN, Phys. Rev. B 74 (2006) 205201.

[37] S. Decoster, B. De Vries, A. Vantomme, U. Wahl, J.G. Correia, Experimental evidence of tetrahedral interstitial and bond-centered Er in Ge, Appl. Phys. Lett. 93 (2008) 141907.

[38] S. Decoster, B. De Vries, U. Wahl, J.G. Correia, A. Vantomme, Lattice location study of implanted In in Ge, J. Appl. Phys. 105 (2009) 083522.

[39] S. Decoster, S. Cottenier, B. De Vries, H. Emmerich, U. Wahl, J.G. Correia, A. Vantomme, Transition metal impurities on the bond-centered site in Ge, Phys. Rev. Lett. 102 (2009) 065502.

[40] S. Decoster, S. Cottenier, U. Wahl, J.G. Correia, and A. Vantomme: "Lattice location of ion implanted Sn and Sn-related defects in Ge", Physical Review B 81 (2010) 155204.

[41] H. Wolf, F. Wagner, Th. Wichert, the ISOLDE collaboration, Anomalous diffusion profiles of Ag in CdTe due to chemical self-diffusion, Phys. Rev. Lett. 94 (2005) 125901.

[42] H. Wolf, F. Wagner, J. Kronenberg, Th. Wichert, R. Grill, E. Belas, the ISOLDE collaboration, Driftdiffusion of highly mobile dopants in CdTe, Diffusion Fundamentals 8 (2008) 3.

[43] Th. Wichert, H. Wolf, Z. Guan, X. Li, Investigation of nanocrystalline materials using radioactive isotopes, Zeitschrift fur Physikalische Chemie 222 (2008) 355.

[44] H. Wolf, J. Kronenberg, F. Wagner, Th. Wichert, the ISOLDE collaboration, Pre-requisites for the formation of unusual diffusion profiles in II-VI semiconductors, Physica Status Solidi B 247 (2010) 1405.

[45] I. Riihimäki, A. Virtanen, S. Rinta-Anttila, P. Pusa, J. Räisänen, the ISOLDE Collaboration, Vacancyimpurity complexes and diffusion of $\mathrm{Ga}$ and $\mathrm{Sn}$ in intrinsic and p-doped germanium, Appl. Phys. Lett. 91 (2007) 91922.

[46] I. Riihimäki, A. Virtanen, H. Kettunen, P. Pusa, P. Laitinen, J. Räisänen, the ISOLDE Collaboration, Elastic interactions and diffusion of Sn in Si1-xGex systems, Appl. Phys. Lett. 90 (2007) 181922.

[47] O. Koskelo, P. Pusa, J. Räisänen, U. Köster, I. Riihimäki, Diffusion of beryllium in Ge and Si-Ge alloys, Journal of Applied Physics 103 (2008) 73513.

[48] I. Riihimäki, A. Virtanen, and H. Kettunen, P. Pusa, J. Räisänen, Diffusion properties of Ga in Si1-xGex alloys, Journal of Applied Physics 104 (2008) 123510.

[49] O. Koskelo, J. Räisänen, U. Köster, I. Riihimäki, Migration kinetics of ion-implanted beryllium in glassy carbon, Diamond and Related Materials 17 (2008) 1991.

[50] O. Koskelo, J. Räisänen, F. Tuomisto, J. Sadowski, the ISOLDE collaboration, The effect of material growth technique on ion implanted Mn diffusion in GaAs, Semiconductor Science and Technology 24 (2009) 045011 . 
[51] G.J. Beyer, T.J. Ruth, The role of electromagnetic separators in the production of radiotracers for biomedical research and nuclear medical application, Nuclear Instruments and Methods in Physics Research B 204 (2003) 694.

[52] L. Hemmingsen, K.N. Sas, E. Danielsen, Biological applications of perturbed angular correlations of -ray spectroscopy, Chem. Rev. 104 (2004) 4027.

[53] O. Iranzo, P.W. Thulstrup, S.B. Ryu, L. Hemmingsen, V.L. Pecoraro, The Application of ${ }^{199} \mathrm{Hg}$ NMR and ${ }^{199 \mathrm{~m}} \mathrm{Hg}$ PAC spectroscopies to define the biological chemistry of $\mathrm{Hg}(\mathrm{II})$ : A case study using designed two and three stranded coiled coils, Chem. Eur. J. 13 (2007) 9178.

[54] U. Heinz, L. Hemmingsen, M. Kiefer, H.W. Adolph, Structural Adaptability of Zinc Binding Sites: Different Structures in Partially, Fully, and Heavy-Metal Loaded States, Chem. Eur. J. 15 (2009) 7350.

[55] N. Selevsek, S. Rival, A. Tholey, E. Heinzle, U. Heinz, L. Hemmingsen, H.W. Adolph, Zinc ion-induced domain organization in metallo- $\beta$-lactamases: A flexible "zinc arm" for rapid metal ion transfer?, J. Biol. Chem. 284 (2009) 16419.

[56] J. Bollmann, M. Thieme, J. Weber, Defect generation by radioactive decay of light elements in n-type silicon, Physica B 376 (2006) 97.

[57] K. Johnston, M.O. Henry, D. Mc Cabe, M. Dietrich, the ISOLDE Collaboration, E. Alves, Identification of donor-related impurities in ZnO, Phys. Rev. B 73 (2006) 165212.

[58] M. Steger, A. Yang, T. Sekiguchi, K. Saeedi, M.L.W. Thewalt, M.O. Henry, K. Johnston, H. Riemann, N.V. Abrosimov, M.F. Churbanov, A.V. Gusev, A.D. Bulanov, I.D. Kaliteevski, O.N. Godisov, P. Becker, H.J. Pohl, Isotopic fingerprints of gold-containing luminescence centers in Si-28, Physica B 404 (2009) 5050.

[59] M. Steger, A. Yang, T. Sekiguchi, K. Saeedi, M.L.W. Thewalt, M.O. Henry, K. Johnston, E. Alves, U. Wahl, H. Riemann, N.V. Abrosimov, M.F. Churbanov, A.V. Gusev, A.K. Kaliteevskii, O.N. Godisov, P. Becker, H.J. Pohl, Isotopic fingerprints of Pt-containing luminescence centers in highly enriched ${ }^{28} \mathrm{Si}$, Phys. Rev. B $81(2010) 235217$. 